\title{
Consistency Matters: The Practice of Clinical Pharmacy
}

\author{
Peter J Zed
}

$\mathrm{F}$ or almost 20 years, I have practised as a clinical pharmacist, trained to deliver pharmaceutical care through the identification, resolution, and prevention of drug-related problems, to improve medication use, and to optimize individual therapeutic outcomes. As I refined my skills as a clinician and built on the training of the many great mentors I had during my early career, I developed a consistent, systematic process of patient care. However, despite establishing a level of comfort in my own process and approach, I have often observed inconsistencies in the manner in which we, as a profession, provide care. This is not to suggest that my process is right or better than those of others, but only that there have been differences and inconsistencies in the manner in which our profession has approached patient care and the delivery of clinical services.

The inconsistencies in patient care processes are most obvious when we compare care delivery in different sectors of the health care system. However, even within institutional pharmacy practice, the process of care is vastly different among clinical pharmacists and between patient care settings. By contrast, such inconsistencies are not as obvious when we explore the processes of care provided by other health care professionals, such as physicians and nurses. In each of these disciplines, the approach to care is far more consistent between practitioners, regardless of the practice setting. For example, a visit to the dentist does not typically engender confusion about expectations for care or the dentist's approach to providing that care. Similarly, patients usually know what to expect when they see their family physician for an annual checkup. Even the most critically ill and injured patients experience consistent processes of care in emergency departments, intensive care units, and operating rooms. Can we say the same for the profession of pharmacy and what we do as health care providers? Unfortunately, many patients do not know what to expect when they encounter a pharmacist, and although I believe that we provide quality care, it is the inconsistent interventions and the inconsistent manner in which we interact with patients and other health care providers that create challenges.
This issue has become even more evident as I have started spending more time and attention on the evolution of our profession, paying particular attention to the changing role of the clinical pharmacist in evolving models of care. Despite my comfort and confidence in what I know well-trained

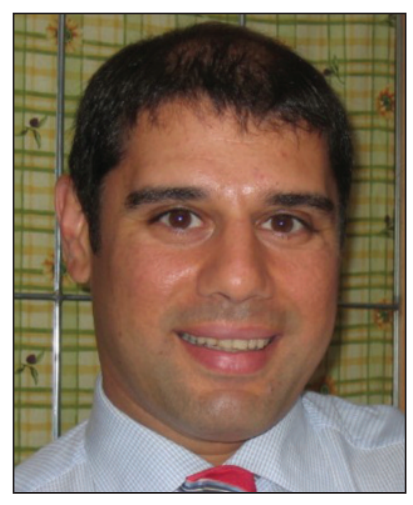
pharmacists can provide in terms of patient care, as well as in the important role we play in health care delivery, I often find myself pausing when I discuss what, exactly, clinical pharmacists do to provide care, and I lack confidence that every patient will experience the same process of care. In addition, inconsistent practice in the pharmacy profession continues to confuse other health care providers, regulators, governments, payers, and, most importantly, patients. If we as a profession cannot define what we do and ensure consistency in how we do it, how can we expect the other stakeholders in health care to understand it and appreciate the value we provide? Even the terminology used to describe our processes of clinical practice contributes to this confusion. Do the terms "pharmaceutical care", "patient-centred care", "medication therapy management", "comprehensive medication management", and other variants mean the same thing, or are there meaningful nuances associated with each of these terms? These many layers of inconsistency have created significant challenges for the successful delivery of clinical pharmacy services, and the diversity in practice has resulted in fractures within our profession and variability in scope of practice and models of pharmacist care.

Clinical pharmacy practice must be defined and its services delivered in a manner that can be applied across all patients and all care settings. In addition, the model of practice should be directly linked to the knowledge, skills, behaviours, and attitudes that are necessary to deliver high-quality pharmacist care using that model. ${ }^{1,2}$ Developing this model will not be easy, 
but doing so will provide a basis for important reform of pharmacy education and training, both for the entry-to-practice degree and for postgraduate training programs, as well as meeting the needs and expectations of patients and other stakeholders in health care. It will also better position the profession to be recognized as a core and essential component of the health care team. This is not a simple matter of terminology but one that requires deeper reflection and purposeful action to address the inconsistencies of what we do as clinical pharmacists. Can we continue to provide services that vary greatly from practitioner to practitioner? Would the health system tolerate a nurse who liked to administer medications but chose not to change wound dressings? Should the health system tolerate a pharmacist who likes perform pharmacokinetic calculations but chooses not to participate in medication reconciliation activities? Are the outcomes of pharmacy practice so nebulous that it doesn't really matter what we do or how we do it? Alternatively, do we know which pharmacy activities make a difference in patient outcomes? If the latter, are we prepared to define evidence-informed practice expectations for pharmacy practitioners in various settings, and ensure that pharmacists adhere to those expectations?

Clinical pharmacy practice has evolved over the past 2 decades, and we have much to be proud of. However, I believe that for the profession of pharmacy to advance to the next level in Canada, and for pharmacists to establish themselves as an essential component of the health care delivery system, a uniform model of clinical pharmacy practice must be agreed upon and consistently employed. Failure to do so will prevent the pharmacy profession from realizing its full potential.

\section{References}

1. American College of Clinical Pharmacy. The definition of clinical pharmacy. Pharmacotherapy. 2008;28(6):816-7.

2. American College of Clinical Pharmacy, Burke JM, Miller WA, Spencer AP, Crank CW, Adkins L, Bertch KE, et al. Clinical pharmacist competencies. Pharmacotherapy. 2008;28(6):806-15.

Peter J Zed, BSC, BSc(Pharm), ACPR, PharmD, FCSHP, is Associate Professor and Associate Dean, Practice Innovation, Faculty of Pharmaceutical Sciences, and Associate Member, Department of Emergency Medicine, Faculty of Medicine, University of British Columbia, Vancouver, British Columbia. He is also an Associate Editor for CJHP.

Competing interests: None declared.

Address correspondence to:

Dr Peter J Zed

Faculty of Pharmaceutical Sciences

University of British Columbia

2405 Wesbrook Mall

Vancouver BC V6T 123

e-mail: peter.zed@ubc.ca

\section{ON THE FRONT COVER}

\section{St. John's, Newfoundland and Labrador}

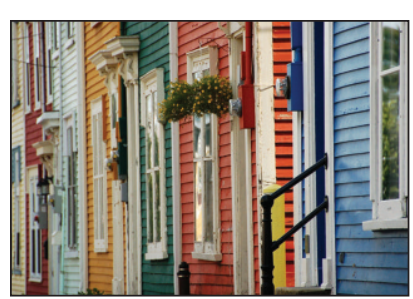

This photo of a vibrant St. John's streetscape was taken on a bright September afternoon. Heather Foley, a hospital pharmacist at Leamington District Memorial Hospital in Leamington, Ontario, captured the scene with a Nikon D60 camera.
The CJHP would be pleased to consider photographs featuring Canadian scenery taken by CSHP members for use on the front cover of the journal. If you would like to submit a photograph, please send an electronic copy (minimum resolution $300 \mathrm{dpi}$ ) to Colleen Drake at cdrake@cshp.ca. 